\title{
Phosphorus supply and management in vegetable production systems in China
}

\author{
Rui WANG ${ }^{1,2}$, Weiming SHI ${ }^{1}$, Yilin LI $(\bowtie)^{1}$ \\ 1 State Key Laboratory of Soil and Sustainable Agriculture, Institute of Soil Science, Chinese Academy of Sciences, Nanjing 210008, China \\ 2 University of Chinese Academy of Sciences, Beijing 100049, China
}

\begin{abstract}
Vegetable production systems involve high rates of chemical and organic fertilizer applications, leading to significant $\mathrm{P}$ accumulation in vegetable soils, as well as a decrease in P use efficiency (PUE), which is one of the key limiting factors in vegetable production. This review introduces the vegetable production systems in China and their fertilization status, and analyzes probable causes of overfertilization of vegetable fields. Poorly developed root systems and high $P$ demand have led to the need to maintain much higher available $P$ concentrations in the root zone for regular growth of vegetables, which might necessitate higher phosphate fertilizer input than the plants require. Research on strategies to improve vegetable PUE and the mechanisms of these strategies are summarized in this review. Increasing the $\mathrm{P}$ uptake by vegetables by supplying $\mathrm{P}$ during the critical growth stage and effectively utilizing the accumulated $\mathrm{P}$ by optimizing the C:P ratio in soils can substantially increase PUE. These advances will provide a basis for improving PUE and optimizing phosphate fertilizer applications in vegetable production through regulatory measures. In addition, some policies are recommended that could ensure the safety of vegetables and improve product quality. This review also aims to improve understanding of $\mathrm{P}$ cycling in vegetable fields and assist in the development of best practices to manage $\mathrm{P}$ reserves globally.
\end{abstract}

Keywords phosphate fertilizer, phosphorus use efficiency, vegetable production systems, phosphorus management, policy recommendation

\section{Introduction}

Vegetables, as major economic crops, are an important component of the human diet, as vegetable contain many

Received April 12, 2019; accepted July 22, 2019

Correspondence: ylli@issas.ac.cn kinds of fiber, carbohydrates, vitamins and minerals ${ }^{[1]}$. With the change in the Chinese dietary practices, the consumption of vegetables has rapidly grown in China. An estimation of consumption data shows that annual vegetable consumption in China was about $96 \mathrm{~kg}$ per capita in $2017^{[2]}$, while total demand for vegetables is predicted to reach $5.9 \mathrm{Mt}$ by 2020 according to the National Vegetable Industry Development Plan (2011$2020)^{[3]}$. Therefore, vegetable production is increasing in China to meet the demand and provide more vegetables to society. The total area of vegetable production in China was about 20 Mha in 2017, which was five times higher than in $1978^{[2]}$. Over the past two decades in China, many rice-wheat rotation fields have been converted to greenhouse production systems in response to the growing demand for vegetables ${ }^{[4]}$.

Vegetable cultivation as an intensive production system is characterized by high inputs and high yields. Vegetable growers routinely apply excessive fertilizers with the intention of increasing profits, with $\mathrm{P}$ application rates exceeding $\mathrm{P}$ removal in harvested fields by several fold ${ }^{[5]}$. Moreover, vegetables receive a higher $\mathrm{P}$ input than cereal crops. Based on data for 13 Chinese provinces from 151 studies published from 1990 to 2018, the amount of phosphate fertilizer applied was about $541.4 \mathrm{~kg} \cdot \mathrm{ha}^{-1} \cdot \mathrm{yr}^{-1}$ for vegetables, which was more than four times that applied to cereal crops ${ }^{[6]}$. However, this practice of phosphate fertilizer application is based on yield goals and it does not consider actual nutritional requirements in vegetable production systems, which has resulted in the accumulation of residual $\mathrm{P}$ and lower $\mathrm{P}$ use efficiency (PUE) in vegetable soils. Khai et al. ${ }^{[7]}$ reported that the surplus of $\mathrm{P}$ ranged from 109 to $196 \mathrm{~kg} \cdot \mathrm{ha}^{-1} \cdot \mathrm{yr}^{-1}$ in smallscale vegetable farming systems in South East Asia. The concentration of $\mathrm{P}$ in vegetable soils was several times higher than that in cultivated soil in northern China ${ }^{[8]}$. Moreover, vegetable production systems involving a high amount of phosphate fertilizer application can lead to significant $\mathrm{P}$ losses to the environment, resulting in water body eutrophication. According to a national-level

(C) The Author(s) 2019. Published by Higher Education Press. This is an open access article under the CC BY license (http://creativecommons.org/licenses/by/4.0) 
analysis, the annual total P (TP) load from open-field vegetable systems in China was 0.33 Mt via runoff ${ }^{[6]}$. Excessive input of $\mathrm{P}$ has also led to land degradation in many areas in China. Therefore, there is an urgent need to develop sustainable vegetable production strategies.

In some vegetable production regions, there have been many studies on $P$ availability and management, especially in terms of vegetable PUE, C:P ratio and threshold values of $\mathrm{P}$ losses in vegetable soils. This review provides an overview of the current status of development in vegetable production systems in China, discusses the possible reasons for overfertilization, introduces approaches to increase the PUE of vegetables and finally proposes some policy recommendations that should be helpful for sustainable development of vegetable production (Fig. 1).

\section{Current development status of vegetable production systems}

\subsection{Status of vegetable cultivation}

Vegetable production systems can be classified into two types: open field systems and greenhouse systems. Openfield vegetables are grown in rotation, typically with two or three crops according to the soil fertility and climate in local production systems. Unlike open-field systems, greenhouse production systems, with special climate conditions and management practices, prolong the growing seasons to produce many kinds of vegetables all year round ${ }^{[9]}$. This type of cultivation practice has rapidly expanded around the world over the last few decades $^{[10-12]}$. Greenhouse production is particularly widespread in Turkey, representing $96 \%$ of total production $^{[13]}$. In China, greenhouse vegetable production was less than 15000 ha in 1983 and has expanded to nearly 4.7 Mha in $2010^{[14,15]}$. Compared with the greenhouse vegetable production in other regions of China, in eastern China with the majority of China's arable land, the area of greenhouse production is much greater, with $22.6 \%$ in Liaoning, $14.2 \%$ in Shandong, $10.9 \%$ in Jiangsu and $10.4 \%$ in Hebei, in $2013^{[16,17]}$.

Greenhouse vegetable production systems in China can be classified into two types in terms of fertilization practices, standard and organic, with the latter using organic fertilizers and no pesticides or growth regulators ${ }^{[18,19]}$. In recent years, organic vegetables have become increasingly popular among consumers because they are free from pesticide residues, and organic vegetables are considered healthy for humans ${ }^{[20]}$. For growers, the attraction of growing organic produce is that it usually attracts a $10 \%-30 \%$ price premium in the market ${ }^{[21]}$. Greenhouse vegetable production systems in China generally follow one of two models of management,

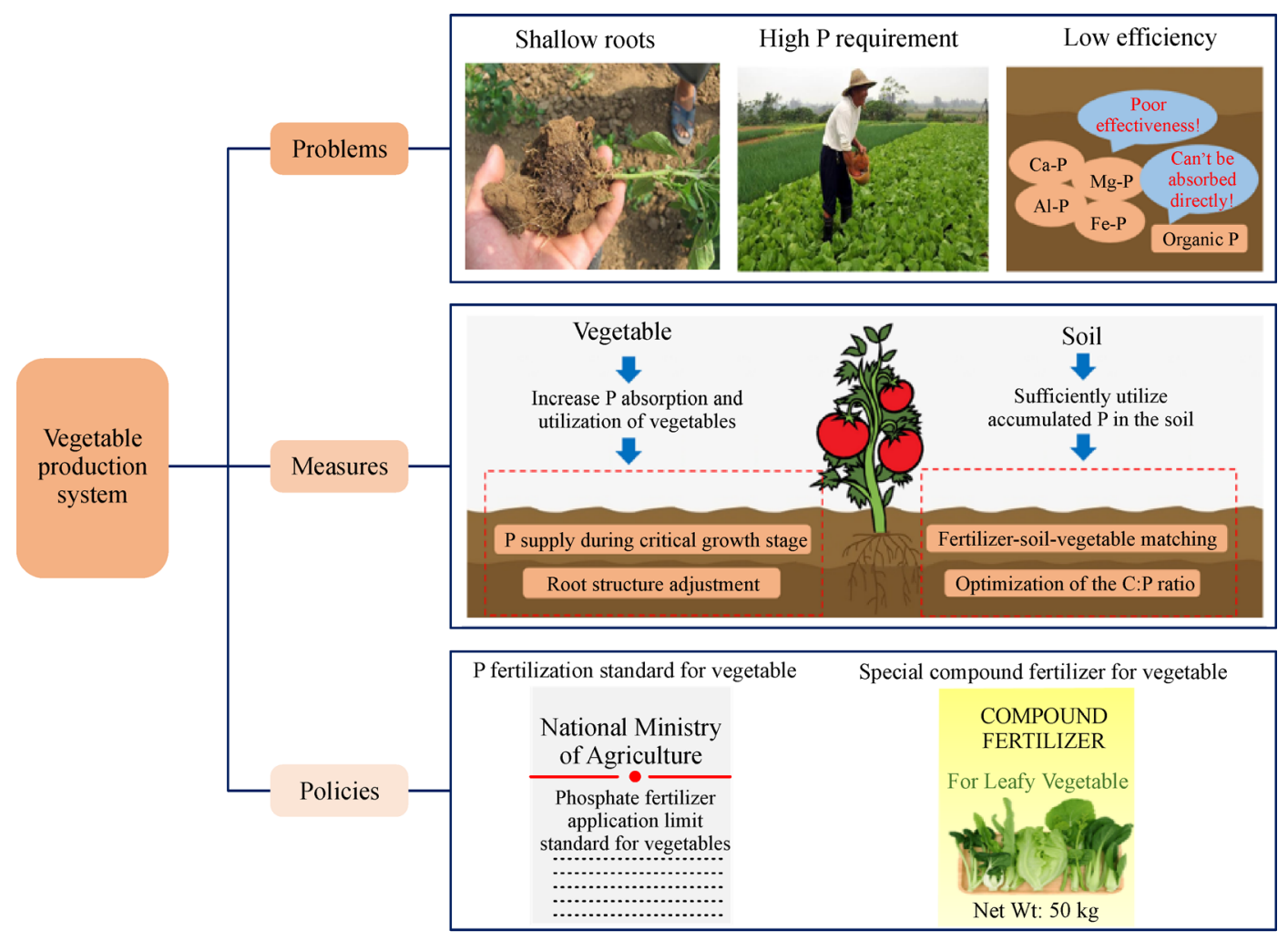

Fig. 1 Schema outlining the causes of overfertilization, approaches to increase PUE and policy recommendation in vegetable production systems. 
household or enterprise management ${ }^{[22]}$. In the family model, management decisions and profits belong exclusively to farmers. Whereas, in the enterprise model, management decisions and profits belong to the management teams, and farmers are generally hired as salaried employees $^{[23]}$.

\subsection{Status of phosphate fertilizer application in vegetable} fields

The relatively high economic value of vegetables has prompted farmers to apply large amounts of fertilizers to obtain maximum yields. Vegetables are the main crops for the application of phosphate fertilizer in China, while the proportion of phosphate fertilizer consumption in vegetables has shown an upward trend compared to wheat and rice and the amount of $\mathrm{P}$ applied to vegetables is approximately $1.7 \times 10^{6} \mathrm{t}_{2} \mathrm{O}_{5}$ in $2017^{[24]}$ (Fig. 2). Survey results indicate that the majority of farmers $(65 \%)$ prefer to use a combination of organic manure and chemical fertilizers in vegetable production systems in $\mathrm{China}^{[23,25]}$. Furthermore, horticultural practices have involved using more organic fertilizers, such as pig and chicken manure, and sewage sludge, especially in greenhouses. Based on data for 16 Chinese provinces from 28 studies published from 2003 to 2009, the proportion of organic phosphate fertilizers applied in greenhouse vegetable production systems was $21.5 \%-65.4 \%$, while in open field, organic phosphate fertilizer accounted for 26.5\%-48.2\%[26] (Fig. 3). These studies showed that livestock manure was used as the basal fertilizer, being uniformly broadcast and incorporated into the topsoil before each crop. In contrast, the chemical fertilizers were generally applied as both basal and topdressed fertilizers $^{[14]}$.

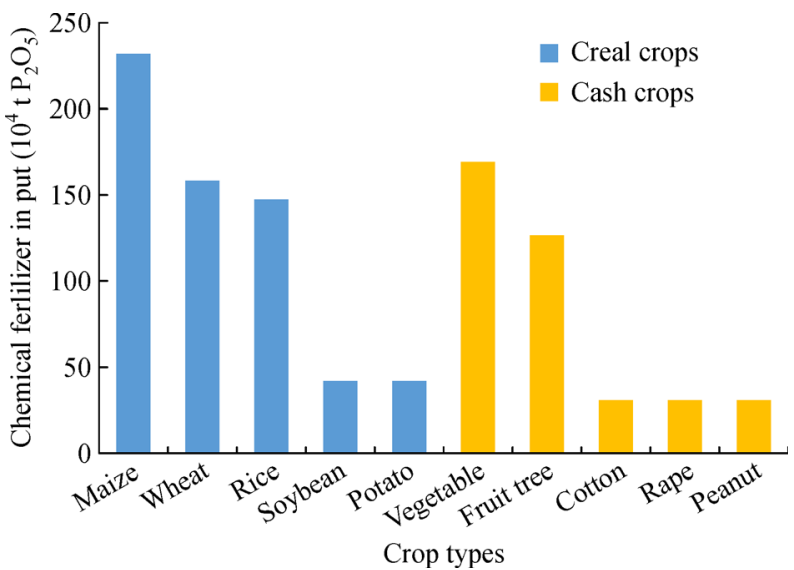

Fig. 2 Total chemical $\mathrm{P}$ application rate of different crops in China during 2017 (calculated from Wang ${ }^{[24]}$ ).

Generally, the N:P ratio of manure $(2: 1)$ is lower than that needed for vegetable uptake $(4: 1-12: 1)^{[27]}$, so continuous applications of manure based on the $\mathrm{N}$ requirements will lead to excessive $\mathrm{P}$ input and a large $\mathrm{P}$ accumulation resulting in a high risk of $\mathrm{P}$ losses to the environment ${ }^{[28]}$. Although contrary to these data, some scholars argue that organic farming represents an environmentally-friendly system ${ }^{[29]}$, while high-external input agriculture is not ${ }^{[30]}$. Large quantities of livestock manure or compost, as a complete substitute for chemical fertilizers, have been a main source of nutrients to fertilize vegetable soils in most organic vegetable production systems. For example, about $2-20 \mathrm{t} \cdot \mathrm{ha}^{-1}$ composted animal manure was applied annually in organic vegetable cultivation in Nanjing, China ${ }^{[31]}$.

\subsection{Characteristics of the phosphorus pool in vegetable soils}

To achieve a high level of economic benefits, long-term repeated application of phosphate fertilizer based on farmer experience rather than on soil analysis and vegetable requirements has resulted in excessive accumulation of $\mathrm{P}$ in vegetable soils. Soil Olsen-P is an important index to indicate the soil $\mathrm{P}$ supply capacity and evaluate the risk of soil $\mathrm{P}$ losses to the surrounding environment ${ }^{[32]}$. An investigation was conducted to determine the soil $\mathrm{P}$ status in greenhouse vegetables, the results showed that the concentrations of Olsen-P varied significantly in different areas, with a mean of $153 \mathrm{mg} \cdot \mathrm{kg}^{-1}$ and the soil $\mathrm{P}$ content reached $328 \mathrm{mg} \cdot \mathrm{kg}^{-1}$ in Xinjiang County in southern Shanxi Province ${ }^{[33]}$. Compared with open-field vegetable production, greenhouse vegetable production provides continuous production all year round with high-intensity inputs and high cropping indexes ${ }^{[34]}$. Therefore, the additive effect of $\mathrm{P}$ occur more clearly in greenhouse soils than in open-field soils. The mean concentrations of TP, Olsen-P, inorganic $\mathrm{P}\left(\mathrm{P}_{\mathrm{i}}\right)$, and organic $\mathrm{P}\left(\mathrm{P}_{\mathrm{o}}\right)$ were higher in greenhouse vegetable soils than in open-field soils. Liu et al. ${ }^{[35]}$ reported that most studies on available $\mathrm{P}$ found higher concentrations in greenhouse soils than in open fields. For example, in Shouguang, Shandong Province, available $\mathrm{P}$ averaged $225 \mathrm{mg} \cdot \mathrm{kg}^{-1}$ in surface soil $(0-20 \mathrm{~cm})$ in greenhouses and was over 10 times higher than in open fields. Also, concentrations of different $\mathrm{P}$ fractions, such as Olsen-P, Ca-P, Al-P and Fe-P, were higher in the surface soils than the subsoil, and the concentrations decreased significantly with increasing soil depth $^{[36]}$. In addition, the concentrations of $P$ in vegetable soils increased with increasing years of production. Li \& Zhang $^{[37]}$ surveyed vegetable topsoil in northern Zhejiang Province and found that TP and Olsen-P were positively correlated with years of production. The concentrations of $\mathrm{TP}$ and Olsen-P in vegetable soil after 30 years of production were about 3.2 and 7.7 times higher, respectively, than those in vegetable soil with less than 2 years of production.

Generally, much higher levels of different $\mathrm{P}$ fractions were observed in vegetable soils than in grain fields due to 
(a)

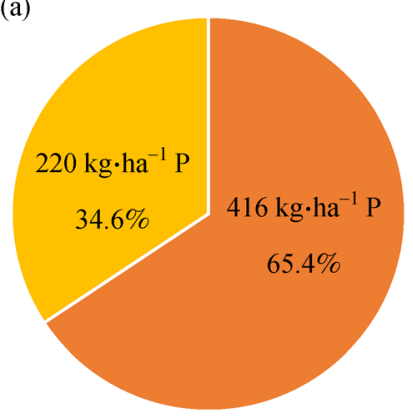

(d)

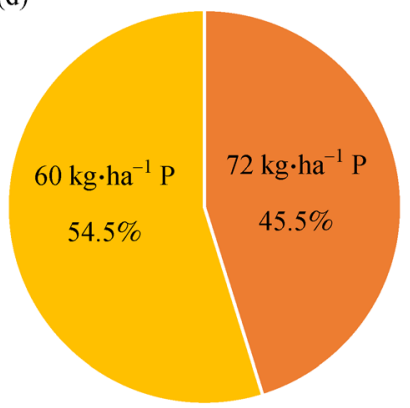

(b)

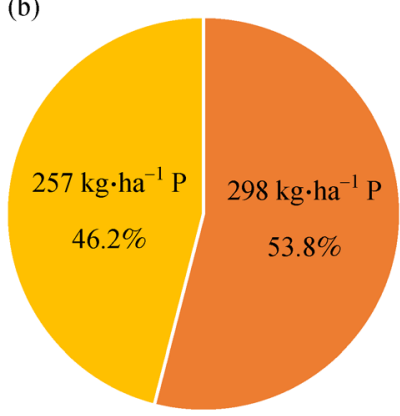

(e)

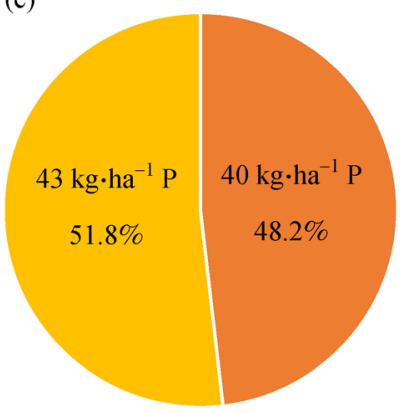

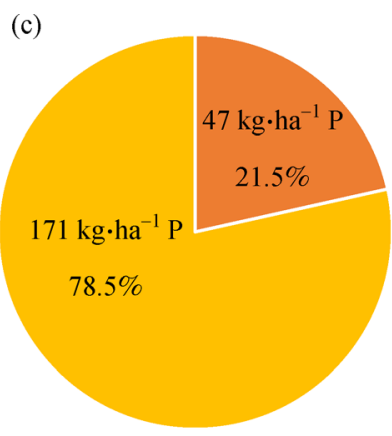

(f)

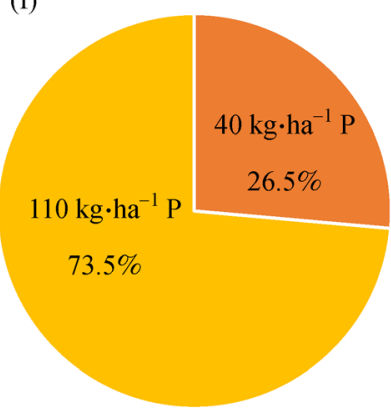

Chemical fertilizer

Organic fertilizer

Fig. 3 Proportion of organic and chemical phosphate fertilizers applied in vegetable production systems in China. (a) Fruit vegetables in greenhouse; (b) melons/squashes in greenhouse; (c) leafy vegetables in greenhouse; (d) leafy vegetables in open field; (e) root vegetables in open field; (f) alliums and ginger in open field. (Calculated from Yan et al. ${ }^{[26]}$ )

the increasing amounts of fertilizer used by farmers in vegetable production ${ }^{[38]}$. For example, the concentration of Olsen-P in vegetable soils was $48.8 \mathrm{mg} \cdot \mathrm{kg}^{-1}$ in the topsoil $(0-20 \mathrm{~cm})$, which was twice as much as that in adjacent grain fields in Hebei, China ${ }^{[39]}$. According to a survey of 34 farm soils in Sydney, Australia, the soils used for vegetable production had extremely high concentrations of TP and $\mathrm{CaCl}_{2}-\mathrm{P}$ with means of 1205 and $4.3 \mathrm{mg} \cdot \mathrm{kg}^{-1}$, respectively, in the $0-30 \mathrm{~cm}$ soil layer, and the concentrations of $\mathrm{CaCl}_{2}-\mathrm{P}$ in fertilized soils were as much as 230 times greater than similar but unfertilized reference soils $^{[40]}$.

\section{Analysis of the causes of overfertilization in vegetable fields}

\subsection{Vegetable roots with shallow morphological characteristics}

The diffusion of $\mathrm{P}$ to the root is the major way that vegetables absorb $\mathrm{P}$, and vegetable roots are characteristically shallow. Furthermore, $\mathrm{P}$ is easily fixed by $\mathrm{Fe}, \mathrm{Al}$ and $\mathrm{Ca}$ in soils ${ }^{[41]}$, and making it largely unavailable for plant uptake. Since vegetables take up $\mathrm{P}$ at a much higher rate than $\mathrm{P}$ diffuses within the root-zone soil, a $\mathrm{P}$ depletion zone is quickly established ${ }^{[42]}$. Therefore, there is spatial dislocation between vegetable root $\mathrm{P}$ demand and $\mathrm{P}$ supply in the root-zone soil.

\subsection{High phosphorus requirement of vegetable crops}

Plant species differ widely in terms of PUE. In comparison to cereal crops, vegetables have a much higher $\mathrm{P}$ demand throughout their growth period. To reach $80 \%$ of their maximum yield, in comparison to wheat, vegetables, such as onion and tomato, require a much higher $\mathrm{P}$ concentration in the soil, and low uptake efficiencies of onion and tomato were associated with a low root-shoot ratio and a low influx rate ${ }^{[43]}$. For example, application of phosphate fertilizer still significantly increased amaranth yield at an Olsen-P level of $74.2 \mathrm{mg} \cdot \mathrm{kg}^{-1}[44]$. In a soil containing an Olsen-P level of $54 \mathrm{mg} \cdot \mathrm{kg}^{-1}$, lettuce yield significantly increased with the application of phosphate fertilizer ${ }^{[45]}$. However, rice yields show no increased response to phosphate fertilizer application when soil Olsen-P is over $21.3 \mathrm{mg} \cdot \mathrm{kg}^{-1[46]}$.

\section{Efficient utilization of phosphorus by vegetable crops}

\subsection{Increased phosphorus absorption and utilization}

\subsubsection{Phosphorus supply during the critical growth stage}

Kinetic parameters, such as maximal uptake rate $\left(\mathrm{V}_{\max }\right)$, are very important characteristics for $\mathrm{P}$ acquisition. $\mathrm{P}$ uptake parameters change continuously with the growth of 
plants ${ }^{[47-49]}$, indicating that $\mathrm{P}$ uptake efficiency varies between different growth stages. Liang et al. ${ }^{[50]}$ found that during cucumber growth $\mathrm{V}_{\max }$ decreased, with the highest value in the initial growth stage. This result means that the $\mathrm{P}$ absorption of cucumber plants was more efficient and critical at the seedling stage that at other stages.

$\mathrm{Qi}^{[51]}$ found that although $\mathrm{P}$ application in seedling soil and in the transplantation periods both significantly promoted cucumber growth, the application in seedling soil was more effective with a significant positive correlation with plant biomass. From 0 to $240 \mathrm{mg} \cdot \mathrm{kg}^{-1} \mathrm{P}$ applied in the seedling stage, significant improvements were found in dry weight, and the effect of increasing biomass reached $100 \mathrm{mg} \cdot \mathrm{kg}^{-1} \mathrm{P}$. Therefore, optimum available $\mathrm{P}$ in the seedling stage of cucumber can maximize crop yields.

\subsubsection{Root density and architecture adjustment}

The root system, as the main interface between the plant and its surrounding soil environment, is important for nutrient and water uptake and storage ${ }^{[52]}$. The plasticity of root morphology is the key characteristic that ensures plants survive in continuously changing environmental conditions ${ }^{[53]}$. For example, root system architecture could be greatly altered upon phosphate depletion, leading to a shallower root system bearing more and longer lateral roots as well as denser root hairs ${ }^{[54]}$. Generally, larger root systems with larger root-surface area, longer root hairs, and greater density of root hairs are closely associated with greater $\mathrm{P}$ uptake efficiency when the soil $\mathrm{P}$ concentration is low ${ }^{[55]}$. Therefore, the adaptation of root morphology is particularly relevant for vegetables when competing for the acquisition of immobile ions such as $\mathrm{P}_{\mathrm{i}}^{[56]}$. Studies have shown that aeration irrigation could significantly promote the growth and activity of vegetable roots. Oxygation (aerating the rhizosphere via the irrigation stream) promotes shallow-rooted crops, such as soybean, to grow to a greater soil depth, as observed by the general increase in root weight and root length density. The effect of oxygation on the yield of shallow-rooted crop vegetables increased yield by $43 \%{ }^{[57]}$. Furthermore, in comparison to non-aerated irrigation, aerated irrigation had significant effects on cucumber growth in a greenhouse in terms of PUE, and root activity increased by $2.4 \%-66 \%{ }^{[58]}$.

\subsection{Sufficient utilization of the accumulated phosphorus in soils}

\subsubsection{Optimization of the C:P ratio}

A large amount of applied manure has led to a decrease in soil C:P ratios, and these ratios in greenhouse soil range from 5.8 to 9.0, which is lower than those in field soil (9.1-
$10.2)^{[59]}$. The lower PUE might be due to the imbalance between $\mathrm{C}$ and $\mathrm{P}$ and might also lead to a lower $\mathrm{P}_{\mathrm{o}}$ mineralization rate ${ }^{[60]}$. The process of soil $\mathrm{P}_{\mathrm{o}}$ turnover depends on soil microbes (especially soil P-solubilizing bacteria) and soil phosphatase activity, which are closely related to soil management practices ${ }^{[61]}$. Biochar, a soil amendment, has emerged as an attractive option to increase $\mathrm{C}: \mathrm{P}$ ratio. With unique physical and chemical properties, biochar has been confirmed to have positive effects on $\mathrm{P}$ availability and reducing $P$ losses in soils by changing the process of $\mathrm{P}$ adsorption and desorption ${ }^{[62]}$. Biochar can also have an important role in soil $\mathrm{P}$ transformations in vegetable soils. Recent studies have indicated that biochar increases $\mathrm{NaHCO}_{3}$ extractable $\mathrm{P}$ and resin $\mathrm{P}$, which are considered the most available for plant growth; soil available $\mathrm{P}$ content is also elevated ${ }^{[63]}$. Moreover, biochar contains a large amount of $\mathrm{P}$, thus, direct release of soluble $\mathrm{P}$ may be necessary to enhance $\mathrm{P}$ availability, especially for short-term use ${ }^{[64]}$.

\subsubsection{Fertilizer-soil-vegetable matching}

$\mathrm{P}$ uptake depends on not only the amount of available $\mathrm{P}$ in soil but also vegetable species and soil types. Some scholars found that in acidic soils, radish had a greater ability to absorb Al-P than Ca-P, whereas in calcareous soils, rape uses Ca-P more efficiently than $\mathrm{Al}-\mathrm{P}^{[65]}$. Different vegetable species have significant variation in their use of different forms of inorganic phosphate; lettuce and spinach have high utilization of Ca-P, while in tomato utilization of Al-P is higher ${ }^{[66]}$. Therefore, sufficient utilization of accumulated $\mathrm{P}$ in vegetable soils could be achieved by some horticultural measures, such as rational rotation or continuous cropping. In comparison to other measures, a pak choi-amaranth rotation uses the $\mathrm{P}$ in $\mathrm{P}$ enriched soils better; results from pak choi-amaranth rotation experiments indicated that soil available $\mathrm{P}$ content and soil water-extractable $\mathrm{P}$ content decreased when the yields of pak choi and amaranth increased ${ }^{[67]}$.

Also, fertilizer-soil matching is important to increase the PUE of vegetables. A large proportion of TP is unavailable to vegetables in calcareous soil due to the rapid fixation of P. Some scholars have found that in comparison to granular phosphate fertilizer, liquid phosphate fertilizer had significantly higher availability, mobility and solubility in calcareous soil and could significantly promote the absorption of $\mathrm{P}$ by plants ${ }^{[68]}$. Chu et al. ${ }^{[6]}$ found that in comparison to the granular $\mathrm{P}$ application, liquid fertilizer application significantly reduced soil $\mathrm{P}$ fixation and increased $\mathrm{Ca}_{2}-\mathrm{P}$ and $\mathrm{Ca}_{8}-\mathrm{P}$; hence, liquid fertilizer improved PUE by $5 \%-15.5 \%$, and the yield of tomato increased by $18 \%-51 \%$. Therefore, regulatory measures that involve fertilizer-soil-vegetable matching and technical integration would be effective for increasing vegetable PUE. 


\section{Policy recommendation}

5.1 Proposed drafting of a limit standard for P application to vegetable soil

We have listed some measures to use P efficiently above, such as adjusting root structure and supplying $P$ during the critical growth stage. Further scientific research could be strengthened by focusing on the relationship between different types of vegetables and soil nutrient status, such as, ensuring that the critical concentrations of Olsen-P for different vegetable species exist in root-zone soil without yield reductions. Another research focus could be whether the soil Olsen-P concentration threshold could be effectively reduced by technologies that improve efficiency. When scientific research has established make sure the optimum fertilization amount, the government, as a management entity, should propose management strategies that include drafting a limit standard for chemical-Pfertilizer application and develop guidance for vegetable production systems based on comprehensively considering local nutrient status and different vegetable $\mathrm{P}$ demands. The government could encourage farmers to follow the rules by paying a targeted subsidy.

\subsection{Producing special compound fertilizers for vegetables}

Farmers prefer to use compound fertilizers in vegetable production systems in China due to the convenience and labor savings associated with them. Generally, the N:P:K ratio of composite fertilizer of $1: 1: 1$ is different from the uptake and demand ratio (1:0.3:1.4). This imbalance in the $\mathrm{N}: \mathrm{P}: \mathrm{K}$ ratio is common in vegetable production systems. The data shows that the application of $\mathrm{P}$ is excessive, while the inputs of $\mathrm{N}$ and $\mathrm{K}$ are low $^{[27]}$. Over-application of $\mathrm{P}$ can, to some extent, increase the content of soluble sugar, vitamin $\mathrm{C}$ and soluble solids ${ }^{[70]}$. Whereas, P-deficiency can cause stunted and short tomato plants, which seriously affects the yield and quality ${ }^{[71]}$. With living standards improving, people are becoming increasingly concerned about vegetable quality and safety. It is important to determine how to ensure the safety of vegetables and improve quality and safety standards, which are not only of interest to the public but also important for improving the competitiveness of the vegetable industry. Therefore, fertilizer producers should be encouraged to produce suitable N:P:K ratios of compound fertilizers based on vegetables nutrient requirements. Vegetable fields, as special production systems, use amount of organic manures or composts as base fertilizer. Thus, the ratio $\mathrm{N}: \mathrm{P}: \mathrm{K}$ of special compound fertilizers should subtract the amount of $\mathrm{N}, \mathrm{P}$, and $\mathrm{K}$ from organic fertilizer according to the local-fertilization habit. This approach could effectively address the problem of unsustainable $\mathrm{P}$ application caused by fertilizing based on $\mathrm{N}$ demand and could also improve vegetable quality. At the same time, the government should accelerate the construction of a new agricultural subsidy policy system, for example by setting a minimum purchase price policy for good-quality vegetables to ensure farmer profits.

China's agriculture has undergone the policy change "zero growth of chemical fertilizer use" to "fertilizer reductions, quality improvements and efficiency increases" proposed by Ministry of Agriculture of the People's Republic of China, which identify the greatest challenges for agricultural production systems. Therefore, strengthening the regulation of vegetable quality by $\mathrm{P}$ management in vegetable production systems is a developing trend for the future.

Acknowledgements This work was supported by the National Key Research and Development Program of China (2017YFD0200200/ 2017YFD0200208), and the National Natural Science Foundation of China (31872957), the Knowledge Innovation Program of the Chinese Academy of Sciences (ISSASIP1608).

Compliance with ethics guidelines Rui Wang, Weiming Shi, and Yilin Li declare that they have no conflicts of interest or financial conflicts to disclose.

This article is a review and does not contain any studies with human or animal subjects performed by any of the authors.

\section{References}

1. Gupta S, Jena V, Jena S, Davić N, Matić N, Radojević D, Solanki J S. Assessment of heavy metal contents of green leafy vegetables. Croatian Journal of Food Science and Technology, 2013, 5(2): 5360

2. National Bureau of Statistics of China (NBSC). China statistical yearbook, 2018. Available at NBSC website on May 1, 2019

3. Zhang Q, Shao N. Domestic vegetable market in 2017 and its prospect for 2018. Agricultural Outlook, 2018, 153(6): 6-10 (in Chinese)

4. Sun B, Dong Z X, Zhang X X, Li Y, Cao H, Cui Z L. Rice to vegetables: short- versus long-term impact of land-use change on the indigenous soil microbial community. Microbial Ecology, 2011, 62 (2): 474-485

5. Huang S W, Jin J Y, Bai Y L, Yang L P. Evaluation of nutrient balance in soil-vegetable system using nutrient permissible surplus or deficit rate. Communications in Soil Science and Plant Analysis, 2007, 38(7-8): 959-974

6. Wang R, Min J, Kronzucker H J, Li Y, Shi W. N and P runoff losses in China's vegetable production systems: loss characteristics, impact, and management practices. Science of the Total Environment, 2019, 663: 971-979

7. Khai N M, Ha P Q, Öborn I. Nutrient flows in small-scale peri-urban vegetable farming systems in Southeast Asia - a case study in Hanoi. Agriculture, Ecosystems \& Environment, 2007, 122(2): 192202

8. Liu J L, Zhang F S, Yang F H. Fractions of phosphorus in cultivated and vegetable soils in northern China. Plant Nutrition and Fertilizer Science, 2000, 6(2): 179-186 (in Chinese) 
9. Sonneveld C, Voogt W. Greenhouse horticulture. In: Sonneveld C, Voogt W, eds. Plant nutrition of greenhouse crops. Dordrecht, the Netherlands: Springer, 2009, 1-11

10. Critten D L, Bailey B J. A review of greenhouse engineering developments during the 1990s. Agricultural and Forest Meteorology, 2002, 112(1): 1-22

11. Liu Z H, Jiang L H, Li X L, Hardter R, Zhang W J, Zhang Y L, Zheng D F. Effect of $\mathrm{N}$ and $\mathrm{K}$ fertilizers on yield and quality of greenhouse vegetable crops. Pedosphere, 2008, 18(4): 496-502

12. Huang S W, Jin J Y. Status of heavy metals in agricultural soils as affected by different patterns of land use. Environmental Monitoring and Assessment, 2008, 139(1-3): 317-327

13. Sungur A, Soylak M, Özcan H. Chemical fractionation, mobility and environmental impacts of heavy metals in greenhouse soils from Çanakkale, Turkey. Environmental Earth Sciences, 2016, 75(4): 334

14. Chen Y, Huang B, Weindorf D C, Yang L Q. Environmental assessment of closed greenhouse vegetable production system in Nanjing, China. Journal of Soils and Sediments, 2013, 13(8): 1418 1429

15. Yang L, Huang B, Hu W, Chen Y, Mao M. Assessment and source identification of trace metals in the soils of greenhouse vegetable production in eastern China. Ecotoxicology and Environmental Safety, 2013, 97(11): 204-209

16. Lei L G, Yuan H M. China agriculture yearbook. Beijing, China: China Agriculture Press, 2014 (in Chinese)

17. Hu W, Zhang Y, Huang B, Teng Y. Soil environmental quality in greenhouse vegetable production systems in eastern China: current status and management strategies. Chemosphere, 2017, 170: 183195

18. Chen Y, Huang B, Hu W Y, Weindorf D C, Liu X X, Yang L Q. Accumulation and ecological effects of soil heavy metals in conventional and organic greenhouse vegetable production systems in Nanjing, China. Environmental Earth Sciences, 2014, 71(8): 3605-3616

19. Forero A F, Escobar H. Effect of conventional and organic vegetable production systems on soil chemical properties in the Bogota plateau (Colombia). Agronomia Colombiana, 2010, 28(3): 411-420

20. Rembialkowska E. Organic farming as a system to provide better vegetable quality. Acta Horticulturae, 2003, 604(604): 473-479

21. Greer L, Diver S. Organic greenhouse vegetable production. Journal of American Association for Pediatric Ophthalmology \& Strabismus, 2000, 14(1): 1-19

22. Li Z Y, Yin H S. The comparison study on household management and enterprise management of facility greenhouse in Shanxi Province. Journal of Shanxi Agricultural Sciences, 2015, 43(10): 1377-1380 (in Chinese)

23. Yang L, Huang B, Mao M, Yao L, Niedermann S, Hu W, Chen Y. Sustainability assessment of greenhouse vegetable farming practices from environmental, economic, and socio-institutional perspectives in China. Environmental Science and Pollution Research International, 2016, 23(17): 17287-17297

24. Wang Y. Production and developing trend of phosphatic compound fertilizer industry in China in 2017. Phosphate and Compound Fertilizer, 2017, 33(6): 1-5 (in Chinese)

25. Lin Z, Routray J K, Zoebisch M A, Chen G, Xie G D, Cheng S K. Three dimensions of sustainability of farming practices in the North
China Plain: a case study from Ningjin County of Shandong Province, PR China. Agriculture, Ecosystems \& Environment, 2004, 105(3): 507-522

26. Yan Z, Liu P, Li Y, Ma L, Alva A, Dou Z, Chen Q, Zhang F. Phosphorus in China's intensive vegetable production systems: overfertilization, soil enrichment, and environmental implications. Journal of Environmental Quality, 2013, 42(4): 982-989

27. Yu H Y, Li T X, Zhang X Z. Nutrient budget and soil nutrient status in greenhouse system. Agricultural Sciences in China, 2010, 9(6): 871-879

28. Zhao Y J, Chen X, Shi Y, Lu C Y, Huang B, Zhao M Q. Impact of fertilization and soil phosphorus status on phosphorus leaching from soil in vegetable greenhouse. Advanced Materials Research, 2013, 610-613: 2968-2973

29. Adebayo S, Oladele I O. Organic agricultural practices among small holder farmers in South Western Nigeria. Organic Agriculture Towards Sustainability, 2014, 51-66

30. Tisdell C. Economic indicators to assess the sustainability of conservation farming projects: an evaluation. Agriculture, Ecosystems \& Environment, 1996, 57(96): 117-131

31. Wang Y L, Zhang H L, Tang J W, Xu J B, Kou T J, Huang H M. Accelerated phosphorus accumulation and acidification of soils under plastic greenhouse condition in four representative organic vegetable cultivation sites. Scientia Horticulturae, 2015, 195: $67-73$

32. Zhang Y C, Li R N, Wang L Y, Zhai C X, Chen L L, Wu X P, Wu H J, Wang X B, Li Y K. Threshold of soil Olsen-P in greenhouses for tomatoes and cucumbers. Communications in Soil Science and Plant Analysis, 2010, 41(20): 2383-2402 (in Chinese)

33. Tang Y, Li L J, Bai G J, Liu P. Investigation and analysis on the current status of fertilization and soil nitrogen and phosphorus accumulation in greenhouse vegetable in Southern of Shanxi. Journal of Shanxi Agricultural Sciences, 2017, 45(5): 773-776 (in Chinese)

34. Xu L, Lu A, Wang J, Ma Z, Pan L, Feng X, Luan Y. Accumulation status, sources and phytoavailability of metals in greenhouse vegetable production systems in Beijing, China. Ecotoxicology and Environmental Safety, 2015, 122: 214-220

35. Liu Z H, Jiang L H, Zhang W J. Evolution of fertilization rate and variation of soil nutrient contents in greenhouse vegetable cultivation in Shandong. Acta Pedologica Sinica, 2008, 45(2): 296-303 (in Chinese)

36. Liu J L, Liao W H, Zhang F H, Gao Z L. Variation and distribution of individual phosphorus pool in the soil profile of vegetable fields. Journal of Agricultural University of Hebei, 2004, 27(6): 6-11 (in Chinese)

37. Li A F, Zhang M K. Accumulation and environmental risk of nitrogen and phosphorus in vegetable soils with different plantation history in Northern Zhejiang. Journal of Agro-Environment Science, 2010, 29(1): 122-127 (in Chinese)

38. Zhang X Y, Chen L D, Li Q, Qi X, Ma Y, Fu B J. Effects of agricultural land-use on soil nutrients and the vertical distributions in traditional cultivated region, Northern China. Journal of AgroEnvironment Science, 2006, 25(2): 377-381 (in Chinese)

39. Liu Y, Peng Z P, Wang Y Q, Ma Y, Men J, Li Y C, Guo L P, Liu S Q, Men M X. Study on the soil characters of vegetable field and 
adjacent grain field in different cinnamon areas. Journal of Agricultural University of Hebei, 2017, 40(6): 21-26 (in Chinese)

40. Chan K Y, Dorahy C G, Tyler S, Wells A T, Milham P P, Barchia I. Phosphorus accumulation and other changes in soil properties as a consequence of vegetable production, Sydney region, Australia. Australian Journal of Soil Research, 2007, 45(2): 139-146

41. McBeath T M, Armstrong R D, Lombi E, McLaughlin M J, Holloway R E. Responsiveness of wheat (Triticum aestivum) to liquid and granular phosphorus fertilizers in southern Australian soils. Soil Research, 2005, 43(2): 203-212

42. Morgan J B, Connolly E L. Plant-soil interactions: nutrient uptake. Nature Education Knowledge, 2013, 4(8): 2

43. Föhse D, Claassen N, Jungk A. Phosphorus efficiency of plants: I. External and internal $\mathrm{P}$ requirement and $\mathrm{P}$ uptake efficiency of different plant species. Plant and Soil, 1988, 110(1): 101-109

44. Liang L Z, Shen R F, Yi X Y, Zhao X Q, Chen Z C, Chen R F, Dong $\mathrm{X} Y$. The phosphorus requirement of Amaranthus mangostanus $\mathrm{L}$. exceeds the 'change point' of P loss. Soil Use and Management, 2009, 25(2): 152-158

45. Johnstone P R, Hartz T K, Cahn M D, Johnstone M R. Lettuce response to phosphorus fertilization in high phosphorus soils. Hortscience A Publication of the American Society for Horticultural Science, 2005, 40(5): 1499-1503

46. Deng J S, Zhang W, Zhu R S, Zhu C Y, Chu Y Y, Li Y. Rice phosphorus fertilizer recommendation system study based on soil available phosphorus. Acta Agriculturae Boreali-occidentalis Sinica, 2011, 20(2): 81-84 (in Chinese)

47. Drew M C, Saker L R, Barber S A, Jenkins W. Changes in the kinetics of phosphate and potassium absorption in nutrient-deficient barley roots measured by a solution-depletion technique. Planta, 1984, 160(6): 490-499

48. Bhadoria P S, Samal D, Steingrobe B, Claassen N. Phosphorus uptake kinetics, root-shoot relations and P-influx of groundnut and maize grown in solution culture. In: Proceedings of the International Plant Nutrition Colloquium XVI, Sacramento, CA. 2009

49. Jungk A, Barber S A. Plant age and the phosphorus uptake characteristics of trimmed and untrimmed corn root systems. Plant and Soil, 1975, 42(1): 227-239

50. Liang L Z, Qi H J, Xu P, Zhao X Q, Dong X Y, Shen R F. High phosphorus at seedling stage decreases the post-transplanting fertilizer requirement of cucumber (Cucumis sativus L.). Scientia Horticulturae, 2015, 190: 98-103

51. Qi H J. Patterns of phosphorus application for cucumber in Penriched garden soil. Dissertation for the Master's Degree. Nanjing, China: Institute of Soil Science, Chinese Academy of Sciences, 2011 (in Chinese)

52. Tian H, De Smet I, Ding Z. Shaping a root system: regulating lateral versus primary root growth. Trends in Plant Science, 2014, 19(7): 426-431

53. Gruber B D, Giehl R F H, Friedel S, von Wirén N. Plasticity of the Arabidopsis root system under nutrient deficiencies. Plant Physiology, 2013, 163(1): 161-179

54. Péret B, Clément M, Nussaume L, Desnos T. Root developmental adaptation to phosphate starvation: better safe than sorry. Trends in Plant Science, 2011, 16(8): 442-450

55. Hu Y F, Ye X S, Shi L, Duan H Y, Xu F S. Genotypic differences in root morphology and phosphorus uptake kinetics in brassica napus under low phosphorus supply. Journal of Plant Nutrition, 2010, 33 (6): 889-901

56. Fitter A, Williamson L, Linkohr B, Leyser O. Root system architecture determines fitness in an Arabidopsis mutant in competition for immobile phosphate ions but not for nitrate ions. Proceedings of the Royal Society of London. Series B, Biological Sciences, 2002, 269(1504): 2017-2022

57. Bhattarai S P, Midmore D J, Pendergast L. Yield, water-use efficiencies and root distribution of soybean, chickpea and pumpkin under different subsurface drip irrigation depths and oxygation treatments in vertisols. Irrigation Science, 2008, 26(5): 439-450

58. Hu D Y. Studies of the mechanisms of improvement in the growth of autumn cucumbers and soil environment with aerated irrigation. Dissertation for the Doctoral Degree. Changsha, China: Hunan Agricultural University, 2014 (in Chinese)

59. Yang H, Xu C C, Cao L H, Shi Y L, Man S, Liu H M. Research on the variation characteristics of $\mathrm{pH}$ and mineral nitrogen concentrations in different planting time polytunnel soils of Milin County in Tibet. Journal of Agro-Environment Science, 2016, 35(12): 23972404 (in Chinese)

60. Fei C, Zhang S R, Liang B, Lin J L, Jiang L H, Xu Y, Ding X D. Characteristics and correlation analysis of soil microbial biomass phosphorus in greenhouse vegetable soil with different planting years. Acta Agriculturae Boreali-Sinica, 2018, 33(1): 195-202 (in Chinese)

61. Richardson A E, Lynch J P, Ryan P R, Delhaize E, Smith F A, Smith S E, Harvey P R, Ryan M H, Veneklaas E J, Lambers H, Oberson A, Culvenor R A, Simpson R J. Plant and microbial strategies to improve the phosphorus efficiency of agriculture. Plant and Soil, 2011, 349(1-2): 121-156

62. Zhou K, Sui Y Y, Xu X, Zhang J Y, Chen Y M, Hou M, Jiao X G. The effects of biochar addition on phosphorus transfer and water utilization efficiency in a vegetable field in Northeast China. Agricultural Water Management, 2018, 210: 324-329

63. Wang R P, Yu W M, Liang J W, Liao X R, Zhan Z S, Li S Y. Effects of modified biochar on soil phosphorus transformation in vegetable fields. Ecology \& Environmental Sciences, 2016, 25(5): 872-876 (in Chinese)

64. Arif M, Ilyas M, Riaz M, Ali K, Shah K, Ul Haq I, Fahad S. Biochar improves phosphorus use efficiency of organic-inorganic fertilizers, maize-wheat productivity and soil quality in a low fertility alkaline soil. Field Crops Research, 2017, 214: 25-37

65. Li J M, Cao Y P. Mobilization and utilization of sparingly soluble $P$ by rape and radish under P-deficiency. Plant Nutrition and Fertilizer Science, 1995, 1(3-4): 36-41 (in Chinese)

66. Yi X Y, Chen Z C, Liang L Z, Zhao X Q. On utilization of different forms of inorganic phosphate by lettuce, spinach and tomato seedlings. Soils, 2009, 41(2): 218-223 (in Chinese)

67. Yi X Y. Utilization of phosphorus in P-enriched vegetable soil. Dissertation for the Doctoral Degree. Nanjing, China: Institute of Soil Science, Chinese Academy of Sciences, 2008 (in Chinese)

68. Holloway R E, Bertrand I, Frischke A J, Brace D M, Mclaughlin M $\mathrm{J}$, Shepperd W. Improving fertilizer efficiency on calcareous and alkaline soils with fluid sources of P, N and Zn. Plant and Soil, 2001, 236(2): 209-219 
69. Chu G X, Li M F, Wei C Z, Hu Y C, Guo X L, Zhang S Y. Influence of liquid and granular phosphorus fertilizer on soil inorganic phosphorus fractions and fertilizer efficiency in calcareous soil. Plant Nutrition and Fertilizer Science, 2009, 15(2): 358-365 (in Chinese)

70. Song J L. Effects of different application proportions of phosphate fertilizer as basal and topdressing on quality of tomato. Hubei Agricultural Sciences, 2009, 48(4): 813-814 (in Chinese)

71. Yu X C, Wang J, Zhu M Y, Jiang J. Molecular mechanism of carbohydrate metabolism participation in tomato response to low phosphorus stress. Molecular Plant Breeding, 2015, 13(12): 28332842 (in Chinese) 